Article

\title{
Experiments of Transpiration Cooling Inspired Panel Cooling on a Turbine Blade Yielding Film Effectiveness Levels over $95 \%^{\dagger}$
}

\author{
Augustin Wambersie ${ }^{1, *}$, Holt Wong ${ }^{1}{ }^{1}$, Peter Ireland $^{1}$ and Ignacio Mayo ${ }^{2}$ \\ 1 Department of Engineering Science, University of Oxford, Oxford OX1 3PJ, UK; holt.wong@eng.ox.ac.uk (H.W.); \\ peterireland@eng.ox.ac.uk (P.I.) \\ 2 Rolls-Royce PLC, Derby DE24 8BJ, UK; mayo@Rolls-Royce.com \\ * Correspondence: augustin.wambersie@eng.ox.ac.uk \\ $+\quad$ This paper is an extended version of our meeting paper published in the 14th European Turbomachinery \\ Conference, Gdansk, Poland, 12-16 April 2021.
}

Citation: Wambersie, A.; Wong, H.; Ireland, P.; Mayo, I. Experiments of Transpiration Cooling Inspired Panel Cooling on a Turbine Blade Yielding Film Effectiveness Levels over 95\% . Int. J. Turbomach. Propuls. Power 2021, 6,16. https://doi.org/10.3390/ ijtpp6020016

Academic Editor: Giovanna Barigozzi

Received: 16 May 2021

Accepted: 26 May 2021

Published: 4 June 2021

Publisher's Note: MDPI stays neutral with regard to jurisdictional claims in published maps and institutional affiliations.

\begin{abstract}
Panels were tested at different locations around the turbine blade, on both suction and pressure surfaces. Three different surface porosities were also tested. Results demonstrated that the approach can be very successful with high levels of film cooling effectiveness, exceeding $95 \%$, achieved using low coolant mass flow rates. Increasing the surface porosity also proved to be an important parameter in the panel's performance. Additionally, staggering the film holes lead to significant positive interactions between individual films, resulting in much improved panel performance.
\end{abstract}

Keywords: transpiration cooling; turbine blade; film cooling; pressure sensitive paint

\section{Introduction}

The need to design turbine blades able to endure the ever increasing temperatures found in the next generation of turbine engines has long motivated continuous improvement in cooling and material technology. However, despite the impressive progress made over the past 80 years, most gains have been slow, incremental improvements of existing technology, with film cooling, thermal barrier coatings and ceramic matrix composites being the few major significant innovations.

While transpiration cooling is not a new concept, it has long been predicted to deliver a step change in cooling performance relative to conventional systems [1]. The very high internal surface area, positive effect on heat transfer coefficient and uniform distribution of cooling films make it theoretically ideal for turbine blade applications. Recent advances in porous $\mathrm{C} / \mathrm{C}-\mathrm{SiC}$ and $\mathrm{CMC}$ have led to a revival in the field of transpiration in aerospace for uses such as rocket nozzle cooling [2], yet momentum in turbine blade technology has lagged behind. While this may be due to the significant constraints in blade design arising from the high thermal, mechanical and cyclical loading, a fundamental understanding of the true potential of transpiration cooling as applied to turbine blades remained mostly unexplored before the present research.

The development of high resolution, non-intrusive measurement techniques has facilitated the study of more complicated external cooling flows, allowing much greater understanding of cooling phenomena in representative conditions. By making use of Pressure Sensitive Paint (PSP) to measure the film effectiveness of transpiration cooling features on turbine geometries, this paper will attempt to demonstrate how such cooling flows behave in engine-representative conditions.

Two separate studies are considered in this paper. The first looks at the performance of a transpiration panel over different locations around the blade, on both suction and pressure surfaces. The second looks to compare several variants of the same panel at the same location. While transpiration cooling has benefits far beyond external film effectiveness, 
the simplicity of this type of experiment allows for a large number of geometries to be quickly sampled, making it a sensible starting point.

\section{Literature Review}

In previous work by Ngetich [3], the effectiveness of full coverage effusion cooling schemes on full turbine blade geometries was tested but with limited success. The introduction of large numbers of large holes across the entirety of the blade surface resulted in a significant flow migration towards the latter portion of the suction surface due to the high pressure gradient across the blade. Combined with the effects of secondary flows, this resulted in very low effectiveness on the pressure surface. Reducing the pitch and increasing the number of holes was seen to noticeably improve the external film effectiveness, though large mass coolant fractions of above $4 \%$ were required.

Several studies have demonstrated the film effectiveness of arrays of more tightly packed holes and porous media, albeit on flat plates. In a study by Murray et al. [4], the effect of hole pitch of effusion cooled plates demonstrated that the for a given coolant output per unit area, reducing the pitch between coolant holes greatly improved the average film effectiveness of the studied plate. Reducing the pitch to hole diameter ratio from 5.75 to 3 more than doubled the effectiveness. When compared to results by Ling et al. [5] in which higher pitch to diameter ratios were used, the improvement in film effectiveness from a pitch of $10 \mathrm{~d}$ to $3 \mathrm{~d}$ was almost sevenfold for the same non dimensional mass flow. CFD modeling of the same domain remains a challenge, with so many interactions between closely spaced films proving difficult to predict. With each additional film row, divergence from experimental data as well as computing time was greatly increased. While simplified analytical approaches such as the one suggested by Sellers [6] can greatly reduce computing time, accuracy remains a challenge, leaving experimental data as the most reliable approach

In another flat plate study by Huang et al. [7] the metal effectiveness of perforated plates was compared to that of sintered porous media in a low speed wind tunnel. Here, it was shown that while perforated plates with higher porosities performed better those with lower porosities, the sintered plates did not have a noticeable improvement in performance despite being almost twice as porous. This suggests that downsizing cooling features is only beneficial up to a point, at which the individual cooling jets become smaller than the boundary layer characteristic length.

While flat plate studies provide a level of insight into the behavior of transpired coolant flows, the nature of the flow around a turbine blade can lead to significant divergence from flat plate studies, particularly in the case of low blowing ratios. Schwarz et al. [8] examined the effect of the curvature to film hole size ratio $2 \mathrm{r} / \mathrm{d}$ on film effectiveness by studying high speed flows around a cylindrical section. It was observed that for highly convex surfaces at low film momentum ratios of 0.5 , the measured film effectiveness was over twice as high as that measured on a flat plate and this increase was closely correlated to the $2 \mathrm{r} / \mathrm{d}$ ratio.

The adverse effect of curvature on film effectiveness was found to be true on concave surfaces. El-Hady \& Verma [9] argue that this is due to additional secondary flows, namely Taylor-Gortler vortices, which have a significant effect on the boundary layer stability and film effectiveness of concave surfaces, due to an increase in film to mainstream mixing.

Winka et al. [10] took the study of convex surfaces further and examined how the non-uniform curvature of an airfoil affected film effectiveness. By comparing several different combinations of hole location and size, it was possible to deduce that the local curvature r, local curvature ratio $2 \mathrm{r} / \mathrm{d}$ and curvature of the entire downstream region play a significant role in the film to mainstream mixing. In this study, a momentum ratio of 0.2 was measured to be the most effective for convex surfaces.

Another effect not considered by either of these studies is the effect of acceleration on the boundary layer. Vinton \& Wright [11] subjected films to favorable pressure gradients resulting in a reduction in the boundary layer thickness, forcing the film core closer to the test surface and leading to improved film effectiveness. 


\section{Experimental Facility}

Experiments were conducted at the Oxford Thermofluids Institute of The University of Oxford. A detailed description of the test apparatus and its operating conditions can be found in the work by Ngetich [3]. The airfoil profile used was a scaled up midsection profile of a high pressure turbine blade. The walls of the cascade are made of thick Perspex for optical access and were designed to achieve the periodic boundary conditions defined by the midpitch streamline in the engine. The facility was designed to match engine Reynolds numbers, as well as match the Mach number distribution predicted by a CFD infinite cascade simulation. The mainstream mass flow rate was calculated to be $1.43 \mathrm{~kg} / \mathrm{s}$.

The test pieces were painted with PSP and monitored using three high resolution CCD cameras. Each was positioned so that their overlapping fields of view could be stitched into a single image covering the entirety of the blade surface. The data capture, processing and uncertainty measurements were carried out as described by Gurram et al. [12].

\section{Blade Geometry and Test Regime}

The test pieces were fabricated in house by $3 \mathrm{D}$ additive manufacturing techniques. The interior of the blades were completely hollow and void of any features. The coolant inlet was a large simple cut into the side of the blade. For this experiment, only the middle $60 \mathrm{~mm}$ of the span was used in order to avoid end wall effects at either end the blade span. The default wall thickness of the blades were kept high, at $5 \mathrm{~mm}$ in order to reduce strain under aerodynamic loading, but was reduced at the panel location in order to produce representative blade wall thickness.

Each test piece contained a panel formed by a large array of $0.5 \mathrm{~mm}$ diameter holes spanning an area of $60 \mathrm{~mm} \times 18 \mathrm{~mm}$. The spanwise pitch was equal to the streamwise pitch and the holes were always angled at $45^{\circ}$ from the surface. The panel was tested at four different locations around the blade, indicated by Figure 1. For the second part of the study, the film hole pitch was changed in order to vary the panel porosity. Lastly a final panel was tested with staggered rows. The full description of all geometries can be found in Table 1 and a detail of Panel 1 can also be found in Figure 1.

The test pieces were fitted with dedicated channels for thermocouples spaced at every $20 \mathrm{~mm}$ along the surface for PSP calculations as well as with pressure tappings to measure the internal plenum pressure.

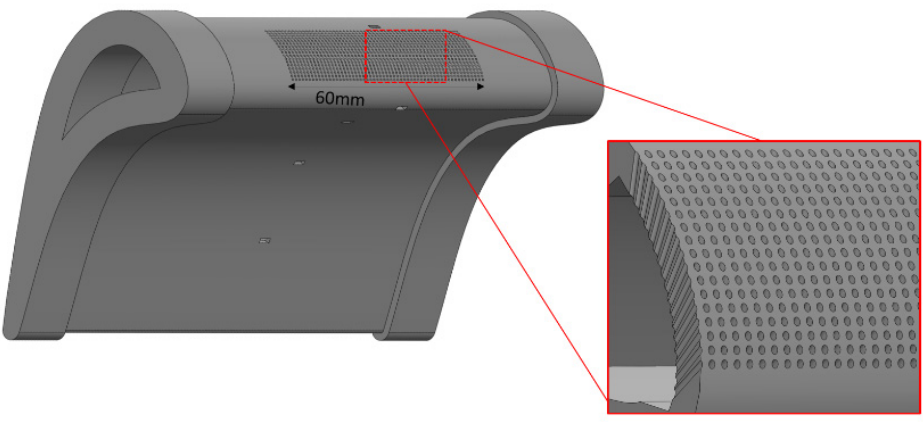

(a)

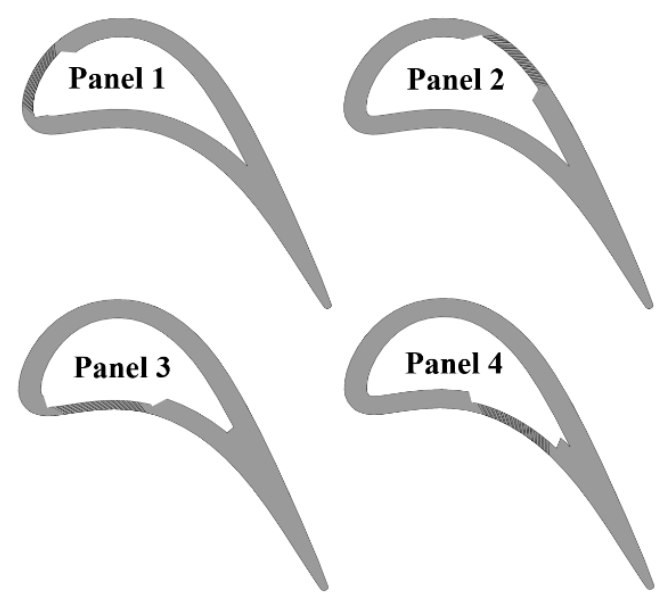

(b)

Figure 1. (a) Detail of Panel 1 geometry with (b) cross section indicating locations of Panels 1-4. 
Table 1. Summary of geometries tested.

\begin{tabular}{cccccccccc}
\hline Panel & Surface & $\begin{array}{c}\text { Pitch } \\
(\mathbf{m m})\end{array}$ & $\begin{array}{c}\mathbf{d} \\
\mathbf{( m m})\end{array}$ & Pitch/d & $\begin{array}{c}\text { L } \\
\mathbf{( m m )}\end{array}$ & L/d & $\begin{array}{c}\text { Streamwise Distance } \\
\text { from LE over Chord }\end{array}$ & $\begin{array}{c}\text { Approximate } \\
\text { Porosity } \\
\mathbf{( \% )}\end{array}$ & $\begin{array}{c}\text { Hole } \\
\text { Arrangement }\end{array}$ \\
\hline 1 & SS & 1.05 & 0.5 & 2.1 & 3 & 6 & 0.1 & 25 & Inline \\
2 & SS & 1.05 & 0.5 & 2.1 & 3 & 6 & 0.64 & 25 & Inline \\
3 & PS & 1.05 & 0.5 & 2.1 & 3 & 6 & 0.1 & 25 & Inline \\
4 & PS & 1.05 & 0.5 & 2.1 & 3 & 6 & 0.33 & Inline \\
5 & SS & 1.20 & 0.5 & 2.4 & 3 & 6 & 0.1 & Inline \\
6 & SS & 0.95 & 0.5 & 1.8 & 3 & 6 & 0.1 & Inline \\
7 & SS & 1.05 & 0.5 & 2.1 & 3 & 6 & 0.1 & 25 & Staggered \\
\hline
\end{tabular}

Each geometry was tested at eight different mass flow rates covering the typical range of mass coolant fractions representative of engine designs. The coolant mass flow rates tested were $5,7.5,10,12.5,15,17.5,20$ and $25 \mathrm{~g} / \mathrm{s}$. This equates to a coolant to mainstream mass fraction ranging from $0.58 \%$ to $2.91 \%$. Turbine blade cooling requirements can range from $2 \%$ to $6 \%$ but most modern first stage HP turbine blades now require a cooling fraction of approximately $4.5 \%$ [13].

Sensor data and the camera inputs were averaged over a period of $5 \mathrm{~s}$ for every measurement in order to obtain a time-averaged result.

\section{Results}

\subsection{Varying Panel Locations}

First, the film effectiveness map of Panels 1-4 across four different blowing rates are shown in Figures $2-5$ respectively. The charts show the entire width of the blade surface from the start of the panel at $x / d=0$ down to the trailing edge. The ratio Pr between the coolant and mainstream inlet total pressures is also shown. The plots are arranged so that the coolant is always being fed from the right side of the image.

For all panels at low blowing rates, film distributions are uneven with coolant only being ejected from certain sections of the panels. This is mainly due to the significant external static pressure variation along the streamwise dimension of the panels. This favors flow towards the trailing edge of Panel 1,2 and 4, and towards the leading edge of Panel 3, where a mild adverse pressure gradient occurs. The low internal pressure results in significant ingestion across the panels. Furthermore, variations in internal static pressure and coolant velocity within the blades lead to uneven spanwise distributions.
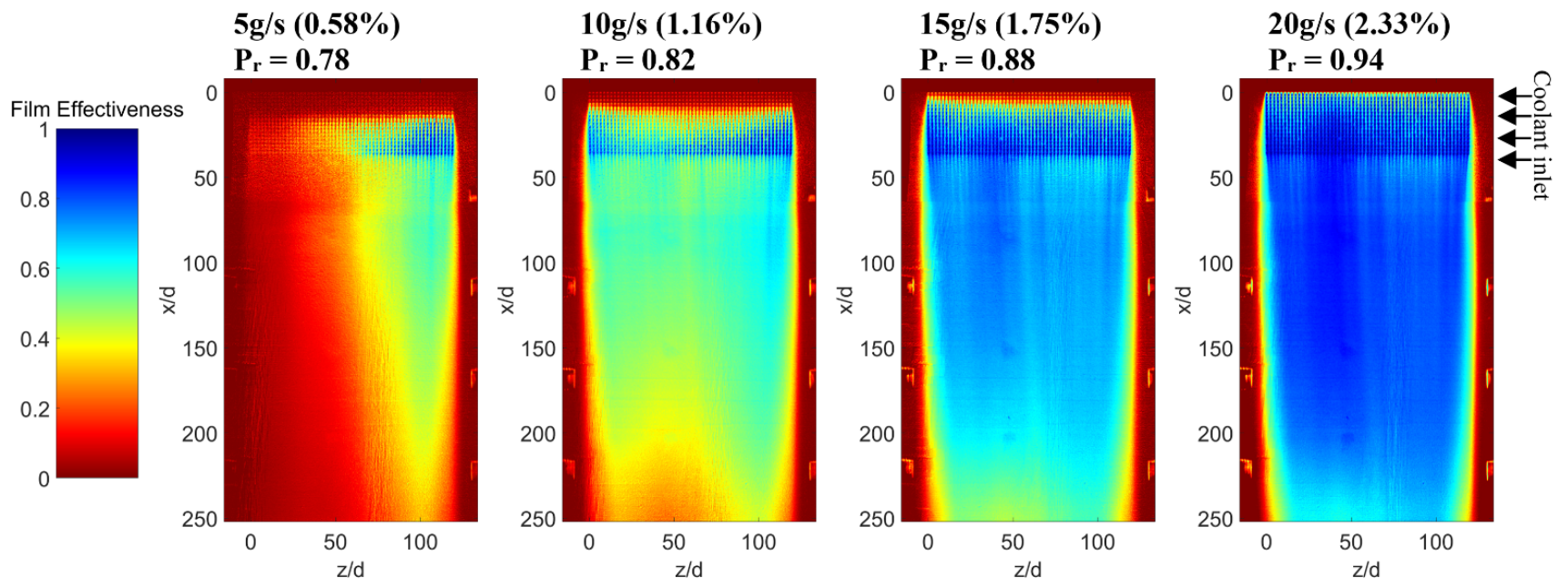

Figure 2. Film effectiveness of Panel 1 at different coolant mass flow rates (mass fraction). 

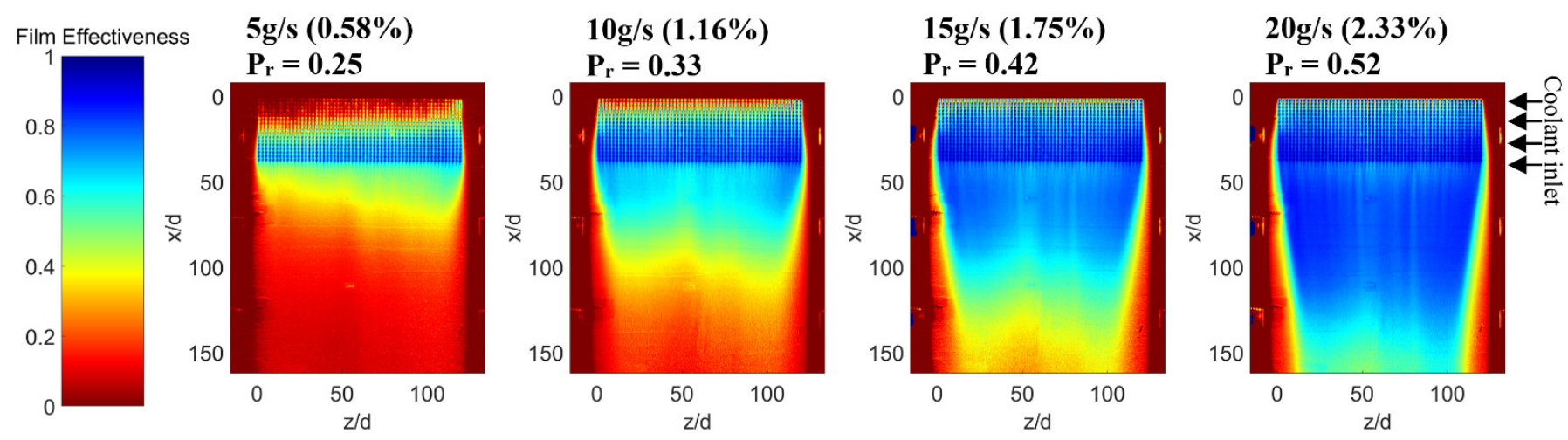

Figure 3. Film effectiveness of Panel 2 at different coolant mass flow rates (mass fraction).
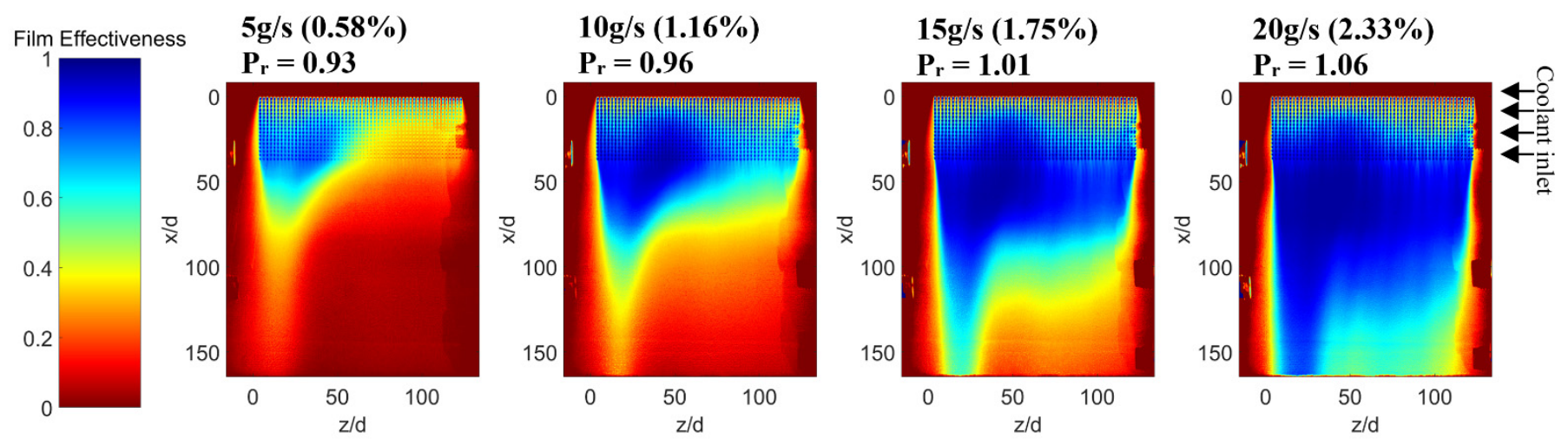

Figure 4. Film effectiveness of Panel 3 at different coolant mass flow rates (mass fraction).
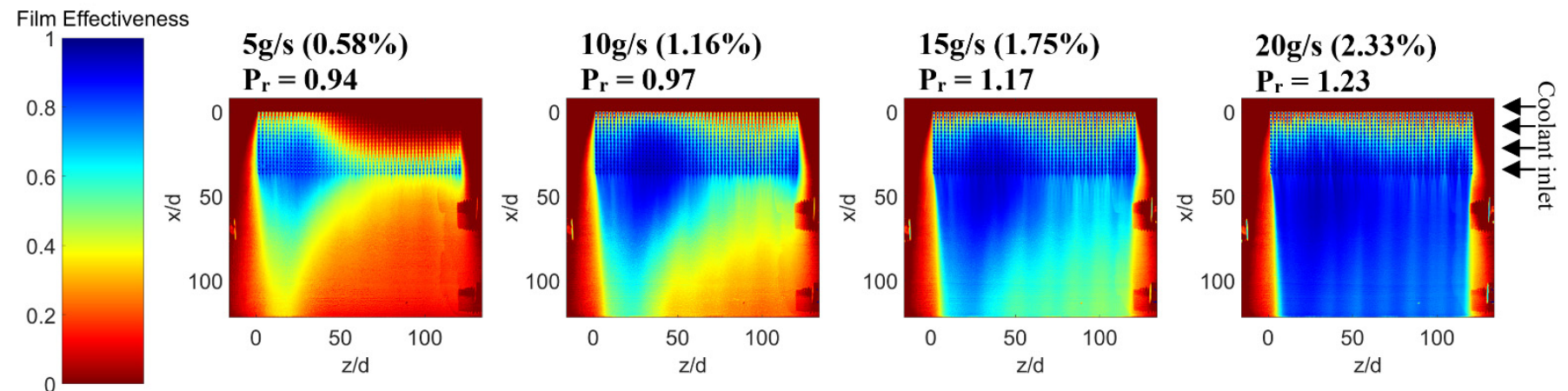

Figure 5. Film effectiveness of Panel 4 at different coolant mass flow rates (mass fraction).

As the coolant flow rate is increased, the distribution is first matched in the spanwise direction and, as the internal blade pressure is further increased, coolant is observed being ejected by every row.

Due to the high resolution of the PSP, the films of the individual holes can be differentiated from the bulk of the coolant. These individual features mix out within a short distance of the end of the panels. On the other hand, the bulk of the panels form a much more robust sheet film.

At the highest mass flows, Panel 1 demonstrates an almost continuous unbroken film, with the entire region downstream of the panel being of a similar film effectiveness. Once above $5 \mathrm{~g} / \mathrm{s}$, the entire span of the panel is fed with coolant, increasing the coolant fraction raises the film effectiveness uniformly across the entire area. This is a sharp contrast to Panel 2, where a higher film effectiveness is achieved immediately downstream of the panel but quickly falls off. Increasing the coolant fraction slowly extends the film further 
downstream, requiring a higher coolant fraction in order to obtain high levels of film effectiveness at the trailing edge.

The difference in films between the two panels can in part be explained by the differences in local mainstream flow. Panel 1, shown in Figure 2, is located in a region of high convex curvature and a significant portion of the downstream region is also convex. Furthermore, these films experience a very high favorable pressure gradient near the panel region. These two effects, combined with the low blowing ratio of the individual holes, result in the films remaining very close to the surface of the blade, with minimal decay. Any disturbances created by the small film jets are small enough to be stabilized by the larger dominant behavior of the mainstream flow. The rate of film decay only begins to increase near the trailing edge region where the curvature flattens out and the flow begins to slow down, increasing the boundary layer thickness as well as the turbulent mixing, resulting in a loss of measured film effectiveness. Evidence of this can be seen in both Panels 1 and 2; the films appear to narrow near the trailing edge as the boundary layers of the sides of the rig grow and push the films toward the middle.

As Panel 2 is positioned further back, it can be seen from Figure 3 that it does not benefit from the early features of the suction surface. On top of the reversal of the pressure gradient, the Mach number at Panel 2 approaches 0.8 , resulting in much more significant film to mainstream interactions within the panel itself.

The two pressure surface panels share a similar trend and distribution with a few notable differences. Both significantly favor the left side, most likely due to the higher internal static pressure inside this half of the blade, opposite the coolant feed. At higher mass fractions, the films start at very high levels but drastically fall off, particularly in Panel 3. This suggests the films follow a trend similar to the wall jet model, with a section of strong potential core in which the film remains mostly untouched by the mainstream, followed by a region of turbulent mixing, which typically dominates most conventional film behavior.

Figure 4 of Panel 3 demonstrates high levels of lateral mixing as the film does not manifest any features reminiscent of the individual holes. In contrast, Figure 5 demonstrates that Panel 4 behaves more like the suction surface panels, with definitive streaks being visible, particularly at the higher mass fractions. This behavior is indicative of the high mainstream flow velocity and strong pressure gradient which dominates the flow. Beyond demonstrating a lack in lateral film spreading, the streaks are also indicative that the panels are not entirely successful in pushing the mainstream away from the surface of the blade as is typically expected in transpiration designs. The square arrangement of holes allows for streams of mainstream air to penetrate through the panels. This is best illustrated in Panel 4 at 15 and $20 \mathrm{~g} / \mathrm{s}$, where visible wakes of mainstream air can be seen compromising a large portion of the downstream film.

Despite these limitations, the overall film effectiveness of all panels remains high for even modest mass flow rates. Once the bulk film is established over the entire span of the panel, a very high average effectiveness is achieved by the spanwise uniformity of the film. This differs from typical film cooling designs that contain hot streaks between film cooling holes, greatly increasing the film to mainstream contact area.

The spatial data can be averaged out laterally, pixel by pixel, in order to obtain a spanwise average of the films as shown by Figure 6 . The averages are only performed over the $120 \mathrm{z} / \mathrm{d}$ midspan of the blade containing the transpiration panel. These plots allow for a greater analysis in the behavior of the films. In these plots the panel location is also indicated by the shaded area.

Immediately downstream of the panels, particularly on the suction surface, film lift-off can be observed. While the average blowing ratios of either panel does not exceed 0.3 , the rows furthest downstream have a higher blowing ratio and the films require approximately $15 \mathrm{~d}$ to recover.

When compared to the other panels, Panel 1 undergoes a much lower rate of film decay, to the point at which the film effectiveness at the trailing edge is higher for Panel 1 
than for Panel 2 for the same mass flow rates. Naturally, the blowing ratio of Panel 2 is lower than that of Panel 1 due to the higher mainstream velocity, yet the fact remains that the suction surface trailing edge is better served by Panel 1 than Panel 2, suggesting a fundamental difference in the structure and stability of the films.
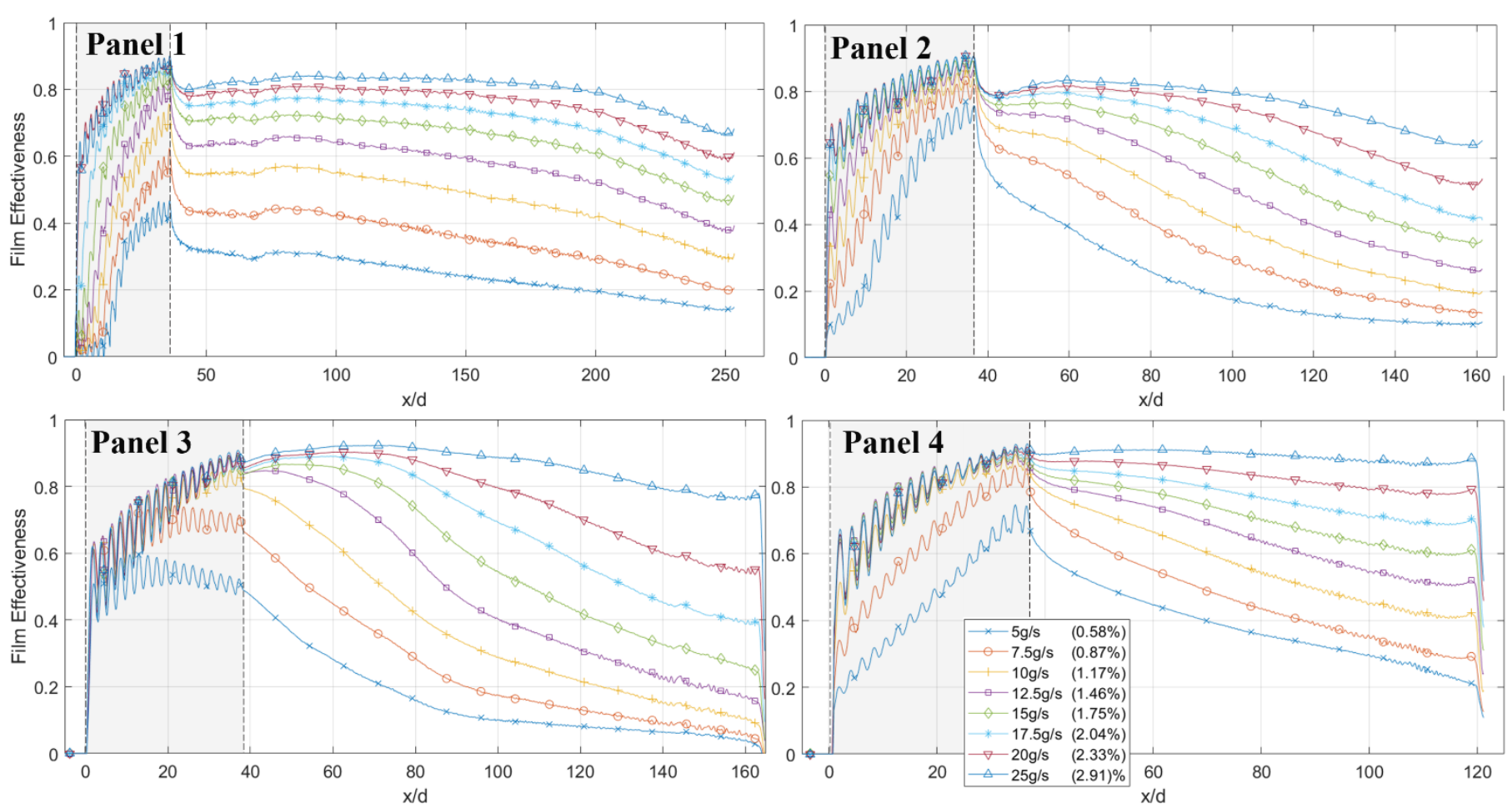

Figure 6. Spanwise average film effectiveness of Panels 1, 2, 3 and 4 at different coolant mass flow rates.

Panels 3 and 4 follow a similar pattern to Panel 2, with some notable differences. Panel 3 is seen to benefit from a much smaller streamwise pressure gradient resulting in no visible ingestion near the leading edge, even at the lowest blowing rates. Panel 4 is seen to perform better than Panel 3, possibly due to the high positive pressure gradient and larger radius of curvature, minimizing the relative effects of destabilizing secondary flows.

The overall shape of the films is also not typically what is expected, with most analytical models predicting an exponential like decay. The results suggest more of a logarithmic decay, particularly in the case of higher blowing rates with the rate of film decay accelerating, instead of leveling off. One possible explanation is that the individual film rows reattach themselves one by one, rebuilding the film after a short period of film lift-off. On the other hand, the strong positive correlation between coolant mass flow rate and film effectiveness across all panels indicates that film lift-off is not yet the dominant mechanism at higher mass flows, as is often the case for conventional film holes.

Another possible reason for the behavior is contained within the tangential injection model for films by Seban and Back [14]. This comparison is not unreasonable given the similarity in performance in flat plate tests between tangential injection and transpiration films as highlighted by Goldstein [15]. According to this model, the films first form a wall jet region in which the films remain intact and only mix with the mainstream flow through diffusion mechanisms. This region is then followed by a region of turbulent boundary layer mixing where film effectiveness is expected to drop off dramatically.

Further justification can be found when considering the secondary flows within the panel films. Conventional films are typically dominated by strong coupled vortex pairs which lift off and then dissipate into the mainstream, as well as allow hot mainstream air to be pulled underneath the film. The quasi 2D behavior of the panel films delays mainstream 
gas from being pulled in from the sides, resulting in a tangential jet like film effectiveness distribution, particularly when good spanwise distribution is achieved.

\subsection{Varying Panel Configuration}

In the second part of the study, different permutations of panel designs were tested in the same location as Panel 1. By changing the hole pitch within the panel, the effective porosity was varied. The effectiveness data of these panels is shown in Figures 7 and 8.
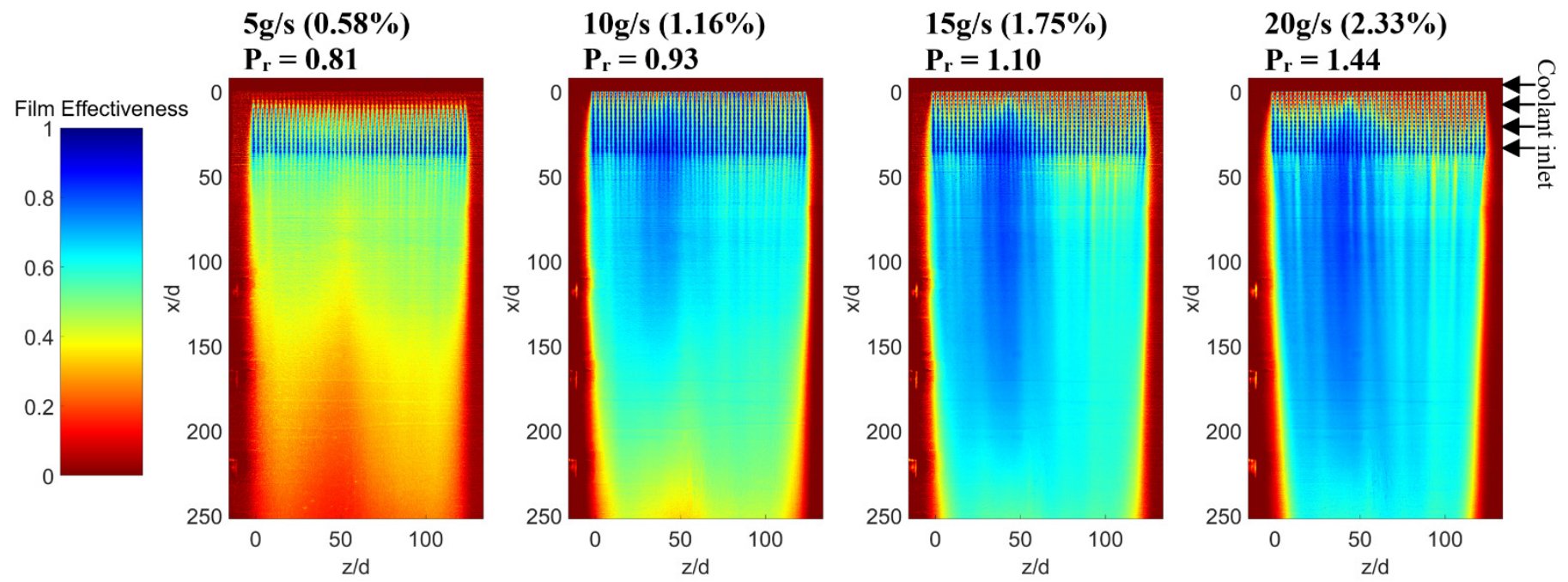

Figure 7. Film effectiveness of Panel 5 at different coolant mass flow rates (mass fraction).
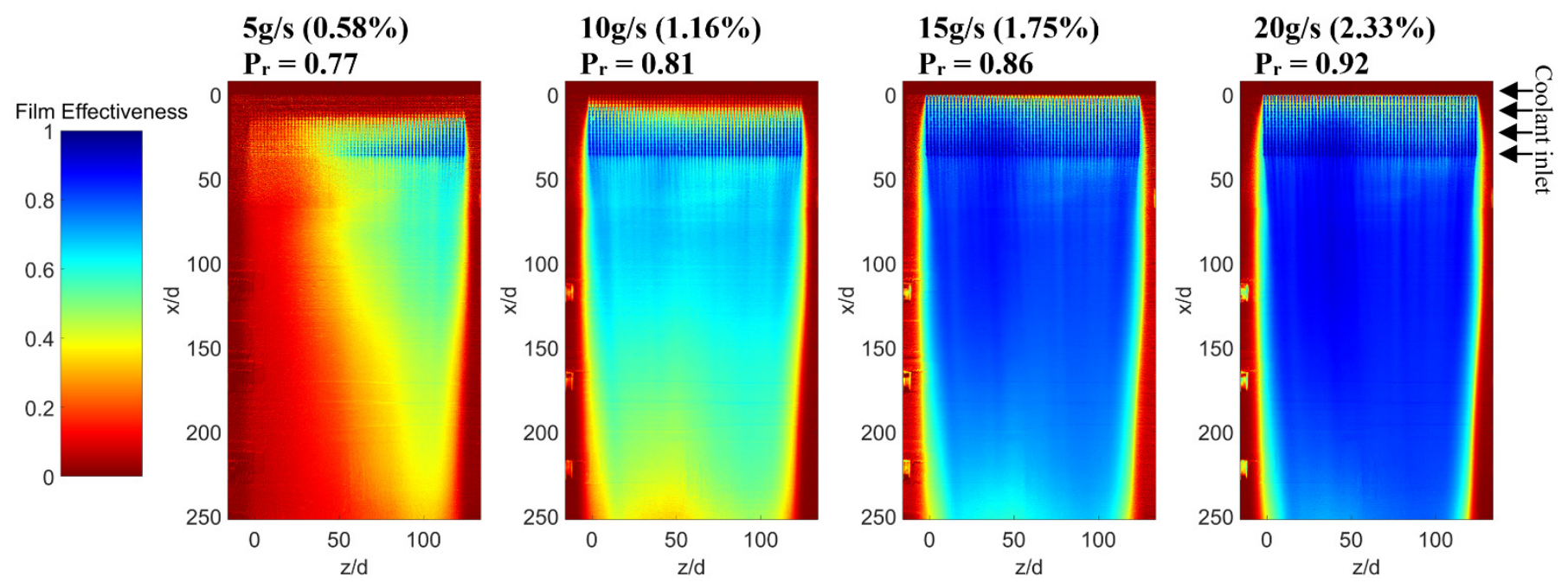

Figure 8. Film effectiveness of Panel 6 at different coolant mass flow rates (mass fraction).

Increasing the pitch, as is the case for Panel 5 reduces the number of holes in the panel. This leads to a more uniform film distribution at a coolant mass flow of $5 \mathrm{~g} / \mathrm{s}$. As coolant mass fraction is increased, the film effectiveness plateaus at a relatively low value. The film is also dominated by significant variations in spanwise effectiveness, which appears as very predominant streaks. With greater spacing in between holes, there is more space for mainstream gas to push its way between the coolant jets and mix with the coolant. This effect is magnified as more coolant is added, with the right side of the panel performing worse at 15 and $20 \mathrm{~g} / \mathrm{s}$ than at $10 \mathrm{~g} / \mathrm{s}$, with defined lines of film effectiveness below 0.4 visible.

Reducing the hole pitches has the opposite effect, with Panel 6 reaching a higher maximum film effectiveness than Panel 1. It is worth noting that the improvement of 
Panel 6 over Panel 1 is much less than that of Panel 1 over Panel 5, indicating diminishing returns as the porosity is increased and the near wall boundary layer becomes saturated with coolant.

The final panel tested was Panel 7, and is shown in Figure 9. Here the pitch was kept the same as Panel 1 but every other row was shifted by half a pitch. Here the film effectiveness rate was measured to be highest across all panels, despite having the same number of holes and blowing ratio as Panel 1 . Here the effect of individual holes can no longer be discriminated and the film appears much more uniform, as there is no path for the mainstream gas to push through the panel. Higher film effectiveness values are also achieved in between the holes of the panel, with the downstream region of the panel essentially obscured from view and saturated at the higher mass fractions. The significant improvement of Panel 7 over the others can also be attributed to the fact that the films are interacting more constructively. With the streamwise pitch essentially doubled, the film jets do not push each other off the surface as is the case with the non-staggered arrangement.
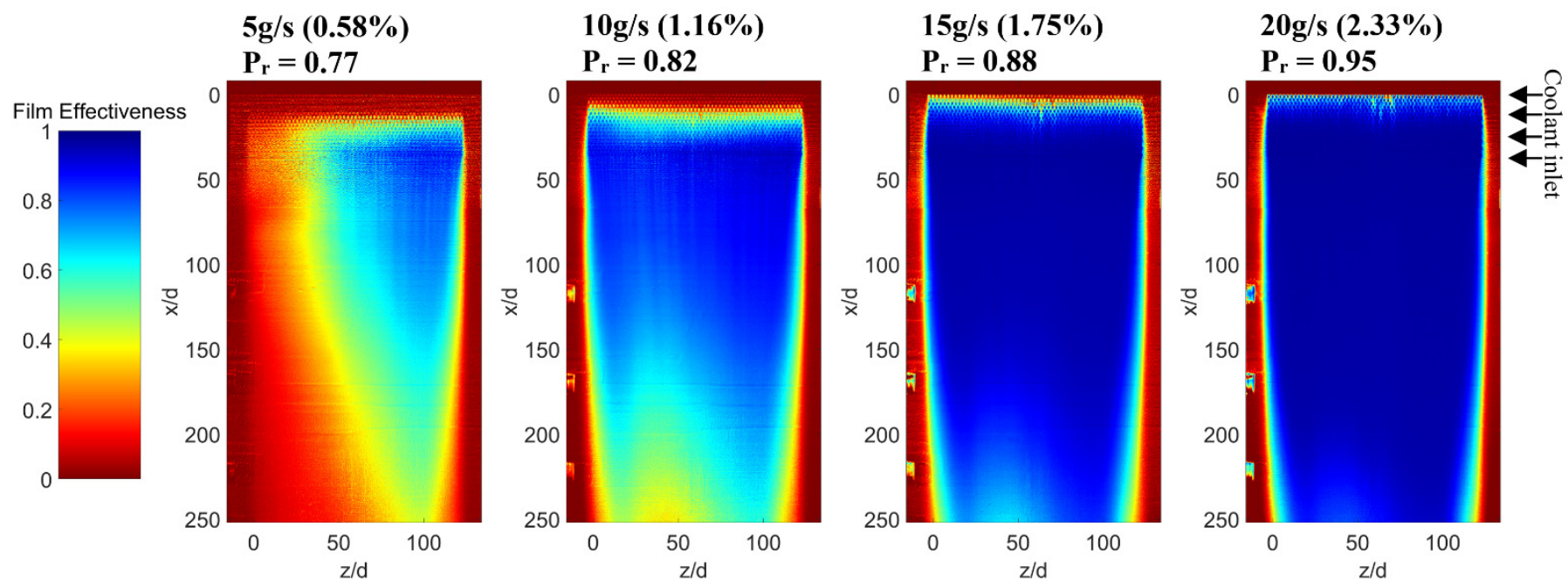

Figure 9. Film effectiveness of Panel 7 at different coolant mass flow rates (mass fraction).

Figure 10 compares the film effectiveness of these panels at $\mathrm{x} / \mathrm{d}=75$ against the calculated average blowing ratio of each panel.

A clear correlation between pitch and film effectiveness can be observed. While Panel 5 has a higher film effectiveness than Panel 1 at mean blowing ratios below 0.1 due to a better spanwise distribution, the maximum film effectiveness achieved does not exceed 0.65 .

The effectiveness of all panels is observed to level off at a mean blowing ratio of approximately 0.2 . This is significantly lower to most conventional film geometries, which tend to reach maximum effectiveness at a blowing of about 0.8 . Additionally, this effectiveness does not drop back down as blowing ratio continues to increase indicating that, overall, film lift-off does not yet dominate the coolant flow.

While not necessarily lifting off, it still can be assumed that the films have reached a saturation point at higher mass flows and that additional coolant would not lead to an improvement in film effectiveness. Therefore the discriminating factor between Panels 1, 5, 6 and 7, is not the ability to add coolant to the boundary layer, but the ability to push the mainstream off of the blade surface. In conventional film theory, this would be equivalent to reducing the mass fraction of mainstream gas within the near wall boundary layer at the end of the panel. 


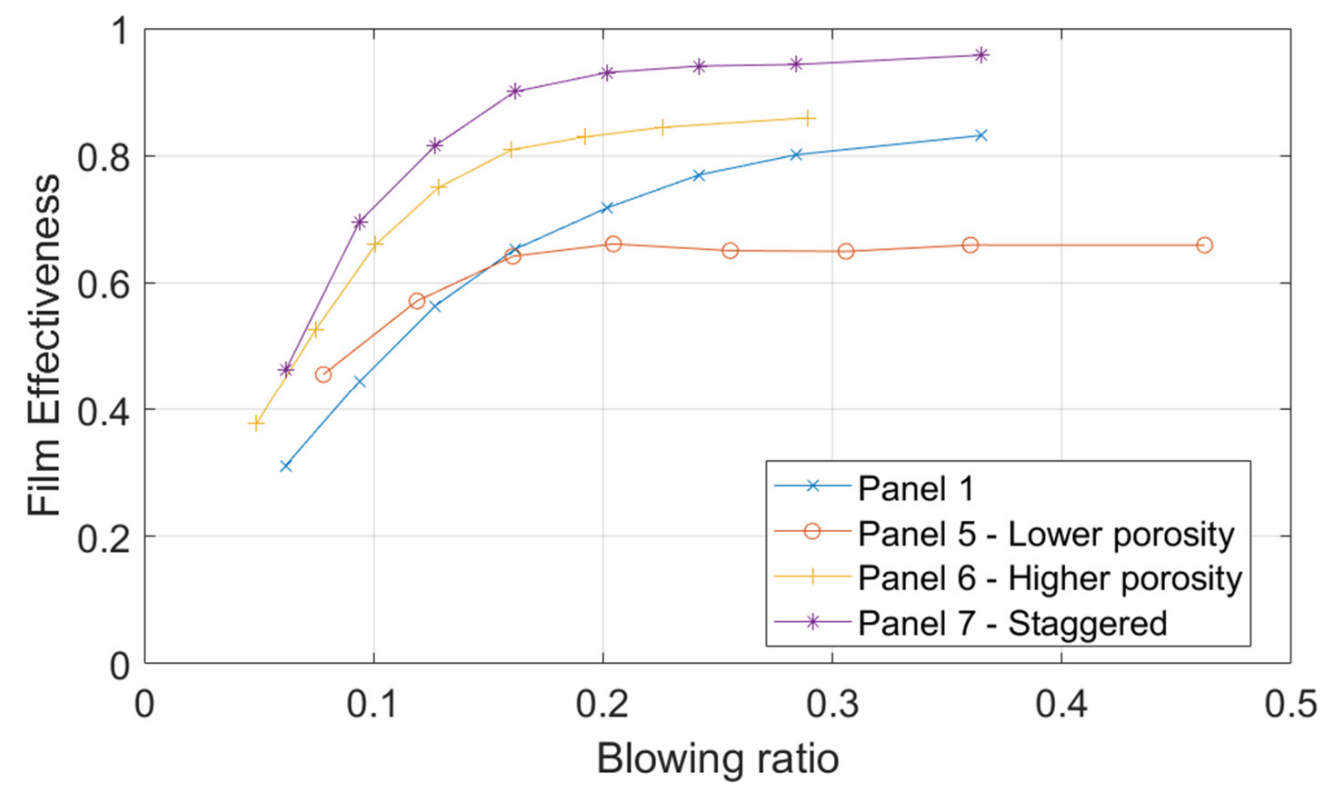

Figure 10. Film effectiveness of Panels $1,5,6$ and 7 at $x / d=75$ at different average blowing ratios.

The consequence of this is that instead of diluting the entrained hot air in the boundary layer with ever increasing mass flows of coolant, a high coolant to mainstream ratio can be achieved with much lower mass flows.

When comparing all of the different Panels at a mass flow for which the film is fully developed, further similarities and differences can be established. As shown by Figure 11, all inline Panels with pitch to diameter ratios of 2.1 share approximately the same film effectiveness at $x / d=40$. At this stage the film effectiveness is dominated by the Panels ability to add coolant to the boundary layer and fend off the mainstream gas. Once past this point, behavior becomes dominated by the particularities of the local mainstream flow such as the rate of boundary layer mixing and mainstream turbulence, with the film cooling geometry having only a minor effect due to the very low blowing ratios used. This is best exemplified by the near parallel behavior of Panels 1 and 5-7, showing that each is affected by the mainstream flow equally.

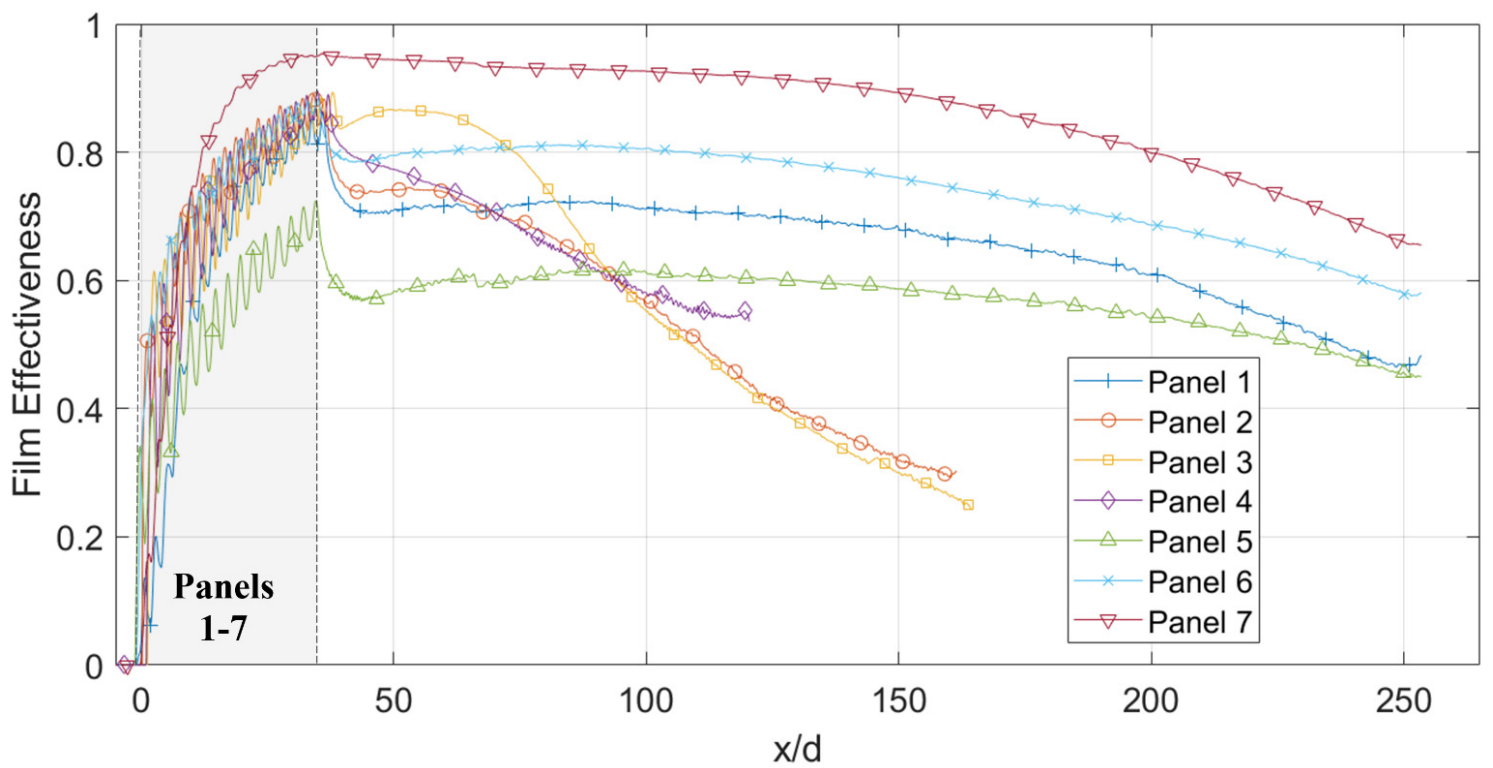

Figure 11. Spanwise average of all Panels at $15 \mathrm{~g} / \mathrm{s}(1.75 \%)$. 


\section{Conclusions}

Very high cooling effectiveness was achieved around the entire blade at very low mass coolant fractions. Films perform particularly well on the early suction surface, which benefits from the effects of curvature and acceleration, resulting in very constant film coverage downstream of the panel. The ability to cool the entire suction side of the blade almost uniformly with a modest coolant fraction is a significant achievement which could warrant diverting additional coolant and attention to this area. While performance on the pressure surface is more modest, particularly around Panel 3, large regions of high film effectiveness were still attained. Divergence from conventional film hole cooling models also implies that the behavior of a large array of small holes cannot be simply extrapolated from single hole studies. Comparisons between different pitches and hole arrangements confirmed that minimizing the spacing between holes can greatly improve the film effectiveness, and suggests that both interactions between individual films and the influence on the mainstream may have a significant impact on film performance. However, it has also been established that the nature of the mainstream flow around a turbine still dominates film cooling behavior once beyond the immediate region of the cooling geometry, particularly on the pressure surface.

The relative simplicity of the designs used leads to a hopeful assumption that transpiration-inspired cooling features are not as remote a concept as previously imagined, though practicalities of implementing transpiration cooling will remain a challenge with issues such as uniform distribution and ingestion still to be solved. Nonetheless, a clear demonstration of its potential has been achieved.

Author Contributions: Conceptualization, A.W. and P.I.; methodology, H.W.; investigation, A.W. and H.W.; writing-original draft preparation, A.W..; writing-review and editing, P.I. and I.M.; supervision, P.I. and I.M. All authors have read and agreed to the published version of the manuscript.

Funding: This work is supported by Rolls Royce plc. and the Transpiration Cooling Systems for Jet Engine Turbines and Hypersonic Flight Programme Grant (EP/P000878/1).

Institutional Review Board Statement: Not applicable.

Informed Consent Statement: Not applicable.

Data Availability Statement: Not applicable.

Acknowledgments: The authors wish to thank the technicians at the Oxford Thermofluids Institute for their contributions in running experiments, as well as Peter Walters for his contributions in improving the additive manufacturing process.

Conflicts of Interest: Rolls-Royce PLC as the funding sponsor provided input to the general scope of interest in the study and the decision to publish the results. They had no direct role in the collection, analyses or interpretation.

\section{References}

1. Eckert, E.; Livingood, J. Comparison of Effectiveness of Convection-, Transpiration-, and Film-Cooling Methods with Air as Coolant; NACA Report 1182; United States Government Publishing Office: Washington, DC, USA, 1954.

2. Langener, T.; von Wolfersdorf, J.; Selzer, M.; Hald, H. Experimental investigations of transpiration cooling applied to C/C material. Int. J. Therm. Sci. 2012, 54, 70-81. [CrossRef]

3. Ngetich, G. Study of film cooling effectiveness on a double walled effusion cooled turbine blade in a high speed flow using pressure sensative paint. In Proceedings of the ASME Turbo Expo Turbomachinery Technical Conference and Exposition, Phoenix, AZ, USA, 17-21 June 2019.

4. Murray, A.V.; Ireland, P.T.; Wong, T.H.; Tang, S.H.; Rawlinson, A.J. High Resolution Experimental and Computational Methods for Modelling Multiple Row Effusion Cooling Performance. Int. J. Turbomach. Propuls. Power 2018, 3, 4. [CrossRef]

5. Ling, J.; Ireland, P.; Turner, L. Full coverage film cooling for combustor transition sections. In Proceedings of the American Society of Mechanical Engineers (ASME) Turbo Expo 2002: Power for Land, Sea, and Air, Amsterdam, The Netherlands, 3-6 June 2002; pp. 1011-1021.

6. Sellers, J.P. Gaseous film cooling with multiple injection slots. AIAA J. 1963, 1, 2154-2156. [CrossRef]

7. Huang, Z.; Xiong, Y.-B.; Liu, Y.-Q.; Jiang, P.-X.; Zhu, Y.-H. Experimental investigation of full-coverage effusion cooling through perforated flat plates. Appl. Therm. Eng. 2015, 76, 76-85. [CrossRef] 
8. Schwarz, S.G.; Goldstein, R.J.; Eckert, E.R.G. The Influence of Curvature on Film Cooling Performance. J. Turbomach. 1991, 113, 472-478. [CrossRef]

9. El-Hady, N.M.; Verma, A.K. Instability of compressible boundary layers along curved walls with suction or cooling. AIAA J. 1984, 22, 206-213. [CrossRef]

10. Winka, J.R.; Anderson, J.B.; Boyd, E.J.; Bogard, D.G.; Crawford, M.E. Convex Curvature Effects on Film Cooling Adiabatic Effectiveness. J. Turbomach. 2014, 136, 061015. [CrossRef]

11. Vinton, K.; Wright, L.M. Effect of Flow Acceleration on Mainstream to Coolant Flow Interaction for Round and Shaped Film Cooling Holes. In Proceedings of the ASME Turbo Expo 2017, Charlotte, NC, USA, 26-30 June 2017.

12. Gurram, N.I. Study of Film Cooling in the Trailing Edge Region of a Turbine Rotor Blade in High Speed Flow Using Pressure Sensitive Paint. In Proceedings of the ASME Turbo Expo 2016: Turbomachinery Technical Conference and Exposition, Seoul, Korea, 13-17 June 2016. ASME Paper No. GT2016-57356.

13. Moustapha, H.; Zelesky, M.; Baines, N.; Japikse, D. Axial and Radial Turbines; Concepts ETI Inc.: White River Junction, VT, USA, 2003.

14. Seban, R.A.; Back, L.H. Effectiveness and Heat Transfer for a Turbulent Boundary Layer with Tangential Injection and Variable Free-Stream Velocity. ASME J. Heat Transfer 1962, 84, 242-244. [CrossRef]

15. Goldstein, R.J. Film Cooling. In Advances in Heat Transfer; Elsevier: Amsterdam, The Netherlands, 1971; pp. 321-379. 